\title{
Sleep duration and hypercholesterolaemia: results from the National Health Interview Survey 2008
}

\author{
Sabanayagam Charumathi and Anoop Shankar ${ }^{*}$ \\ Department of Community Medicine, West Virginia University School of Medicine, Morgantown, \\ WV, USA
}

\begin{abstract}
Background-Previous studies have shown an inconsistent association between sleep duration and hypercholesterolaemia. This study examined the association between sleep duration and hypercholesterolaemia in a nationally representative sample of US adults.

Methods-A cross-sectional study of 16,652 participants in the 2008 National Health Interview Survey (aged $\geq 18$ years, $52.5 \%$ women) was conducted. Sleep duration was categorized as $\leq 5,6$, 7,8 or $\geq 9 \mathrm{~h}$. Hypercholesterolaemia $(n=5578)$ was assessed by questionnaire.

Results-A significant gender difference was found in the association between sleep duration and hypercholesterolaemia $(P$ interaction $=0.0003$ ). Among women, sleep duration $\leq 5 \mathrm{~h}$ was positively associated with hypercholesterolaemia after adjusting for potential confounders and mediators including physical activity, psychological distress, body mass index, diabetes mellitus and hypertension. Compared with a sleep duration of $7 \mathrm{~h}$ (referent), the multivariate odds ratio (OR) of hypercholesterolaemia was 1.27 [95\% confidence interval (CI) 1.04-1.54] for sleep duration $\leq 5 \mathrm{~h}$. In contrast, among men, sleep duration $\geq 8 \mathrm{~h}$ was inversely associated with hypercholesterolaemia. Compared with a sleep duration of $7 \mathrm{~h}$ (referent), the multivariate OR of hypercholesterolaemia was 0.80 (95\% CI 0.69-0.94) and 0.78 (95\% CI 0.60-1.00) for sleep durations of 8 and $\geq 9 \mathrm{~h}$, respectively. In subgroup analyses, the positive association between sleep duration $\leq 5 \mathrm{~h}$ and hypercholesterolaemia in women, and the inverse association between sleep duration $\leq 8 \mathrm{~h}$ and hypercholesterolaemia in men were more pronounced among those aged $<60$ years and race/ethnic groups other than non-Hispanic Whites.
\end{abstract}

Conclusion-Sleep duration $\leq 5 \mathrm{~h}$ was positively associated with hypercholesterolaemia in women, whereas sleep duration $\geq 8 \mathrm{~h}$ was inversely associated with hypercholesterolaemia in men.

\section{Keywords}

Sleep; Sleep duration; Cholesterol; Gender; Ethnicity; NHIS

\begin{abstract}
(C) 2011 Elsevier B.V. All rights reserved.
"Corresponding author. Address: Department of Community Medicine, West Virginia University School of Medicine, Robert C. Byrd Health Sciences Center, 1 Medical Center Drive, PO Box 9190, Morgantown, WV 26505-9190, USA. Tel.: +1 304 293 0199; fax: +1 304293 6685. ashankar@hsc.wvu.edu (A. Shankar).

This is a PDF file of an unedited manuscript that has been accepted for publication. As a service to our customers we are providing this early version of the manuscript. The manuscript will undergo copyediting, typesetting, and review of the resulting proof before it is published in its final citable form. Please note that during the production process errors may be discovered which could affect the content, and all legal disclaimers that apply to the journal pertain.
\end{abstract}

Conflict of interest statement

None declared 


\section{Introduction}

Recent epidemiological studies suggest that sleep duration is a risk factor for cardiovascular disease (CVD) [1-3]. Both short and long durations of sleep are linked to major CVD risk factors including diabetes [4,5], hypertension [6] and obesity [7,8]. Hypercholesterolaemia is an established risk factor for CVD [9]. Experimental studies have shown that sleep restriction and fragmentation have an adverse effect on the lipid profile in healthy volunteers $[10,11]$. However, previous population-based studies that examined the association between sleep duration and hypercholesterolaemia have not found a consistent pattern of association [12-17]. While some studies reported a positive association between hypercholesterolaemia and short [13] or long [16] sleep duration or both [14,17], one study found an inverse association between hypercholesterolaemia and long sleep duration [14], and two studies reported no association between hypercholesterolaemia and sleep duration [12,15]. Further, most of these studies were conducted in specific population groups including adolescents [13], elderly people [16], men [15] or people with diabetes [17]. In addition, some studies reported a gender difference in the association between sleep duration and hypercholesterolaemia $[13,14]$. Gangwisch et al. reported an association between short sleep duration and hypercholesterolaemia in adolescent females but not in males [13]. Kaneita et al. reported a U-shaped association between sleep duration and hypercholesterolaemia in women, and a protective association between long sleep duration and hypercholesterolaemia in men in Japan [14]. The current study tested the hypothesis that, compared with sleep duration of $7 \mathrm{~h}$, shorter and longer sleep durations are associated with hypercholesterolaemia, independent of confounding factors, and there are gender differences in this association.

\section{Methods}

The data for this study were derived from the 2008 National Health Interview Survey (NHIS), and details of the study design, questionnaire and methods are available online [18]. In brief, the NHIS is a multistage probability sample of the civilian, non-institutionalized population of US adults. Blacks, Hispanics and Asians were oversampled to provide stable estimates for these groups. The current study is based on the sample adult core component of the NHIS, administered by in-person interviews with civilian adults (aged $\geq 18$ years) selected at random. Of the 29,370 adults eligible for the sample adult questionnaire, 21,781 adults completed the interviews (response rate 62.6\%). The question on cholesterol was introduced as a supplemental question to the core hypertension and heart disease questions in the 2008 NHIS. Of the 21,781 adults interviewed, 17,111 had information on hypercholesterolaemia. After excluding participants who were pregnant $(n=150)$, those with missing information on sleep duration $(n=243)$ and other variables included in the multivariable analysis ( $n=66), 16,652$ individuals were included in the current analysis. Written informed consent was obtained from all participants, and the study was approved by the West Virginia University Institutional Review Board.

Sleep duration was assessed by asking participants the following question: 'On average, how many hours of sleep do you get in a 24-h period?' Responses were categorized into five groups for the current analysis: $\leq 5,6,7,8$ and $\geq 9 \mathrm{~h}$. Fractional hour responses were rounded to the nearest hour.

Information on demographic, socio-economic and lifestyle characteristics, and health status was collected using a questionnaire. Age was included as a continuous variable. Education was categorized into less than high school, high school and more than high school. Cigarette smoking was classified into never, former and current smoker. Alcohol consumption was categorized into never, former and current drinker. Body mass index (BMI) was calculated 
with self-reported height and weight (weight in $\mathrm{kg}$ divided by height in $\mathrm{m}^{2}$ ). Physical activity was defined based on the 2008 Physical Activity Guidelines for Americans published by the Centers for Disease Control and Prevention [19] as engaging in 150 ( $\geq 30$ min for $\geq 5$ days/week) min of moderate-intensity aerobic activity and muscle-strengthening activities $\geq 2$ days/week, or 75 ( $\geq 25$ min for $\geq 3$ days/week) min of vigorous-intensity aerobic activity and muscle-strengthening activities $\geq 2$ days/week, or a combination of moderate- or vigorous-intensity aerobic activity and muscle-strengthening activities $\geq 2$ days/week. Participants were considered to be inactive if they failed to meet either of these requirements. Diabetes was defined as a 'yes' response to the question: 'Have you ever been told by a doctor or health professional that you have diabetes or sugar diabetes?' Hypertension was defined as self-reported hypertension or high blood pressure. Psychological distress was assessed using the K6 scale [20], including whether the participant experienced feelings of sadness, nervousness, restlessness, hopelessness, worthlessness or that everything was an effort in the past 30 days. Based on the possible responses, a scoring of $0-4(0=$ none of the time, $4=$ all of the time $)$ was assigned, yielding a total score of 0-24. Participants with a K6 score $\geq 13$ were classified to have psychological distress. Hypercholesterolaemia was ascertained by an affirmative response to the question, 'Have you ever been told by a doctor or health professional that your blood cholesterol level was high?'

\subsection{Statistical analysis}

As previous studies have documented gender differences in the association between sleep duration and hypercholesterolaemia [13,14], and the present authors observed an interaction in this association with gender in preliminary analyses $(P$ interaction $=0.0003$ ), all analyses were performed separately for men and women. The characteristics of the study participants were compared by gender using Chi-squared test or analysis of variance, as appropriate. Odds ratios (OR) and 95\% confidence intervals (CI) of hypercholesterolaemia associated with various sleep durations were calculated using $7 \mathrm{~h}$ of sleep as the referent category in three logistic regression models with progressive levels of adjustment. Seven hours of sleep was chosen as the referent category as previous studies have documented lower risks of CVD [1,2] and mortality [21,22] among those with sleep duration of $7 \mathrm{~h}$. The first model adjusted for age (years). Multivariable model 1 also adjusted for potential confounders, including race/ethnicity (non-Hispanic White, non-Hispanic Black, Mexican American, other), education (less than high school, high school, more than high school), smoking (never, former, current), alcohol intake (never, former, current), physical inactivity (absent, present) and psychological distress (absent, present). Multivariable model 2 further adjusted for potential mediators of the association between sleep duration and hypercholesterolaemia, including overweight/obesity (absent, present), diabetes (absent, present) and hypertension (absent, present). In order to examine the consistency of the association between sleep duration and hypercholesterolaemia, stratified analyses were performed by age and race/ ethnicity. Interactions were formally evaluated by the inclusion of cross-product interaction terms in the corresponding multivariable models. All analyses were weighted to account for the complex survey design and survey non-response using SAS-callable SUDAAN Version 9.0 (Research Triangle Institute, Research Triangle Park, NC, USA).

\section{Results}

Table 1 shows the characteristics of the study participants by hypercholesterolaemic status. Participants with hypercholesterolaemia were more likely to be older, non-Hispanic Whites, less than high school education, former smokers, former drinkers, physically inactive and overweight/obese, and to have a higher prevalence of psychological distress, diabetes and hypertension. Table 2 shows the characteristics of the study participants by sleep duration. 
Compared with those with sleep duration of $7 \mathrm{~h}$, those with a longer or shorter sleep durations were more likely to be older, female, less than high school education and current smokers; to have a higher prevalence of obesity, psychological distress, diabetes and hypertension; and were less likely to be non-Hispanic Whites and current drinkers.

Table 3 shows the association between sleep duration and hypercholesterolaemia for men and women. The prevalence of hypercholesterolaemia did not differ by gender $(P=0.9)$. Among women, there was a positive association between sleep duration $\leq 5 \mathrm{~h}$ and $\geq 9 \mathrm{~h}$ and hypercholesterolaemia in the age-adjusted model. Additional adjustment for covariates in multivariable model 1 and mediators in multivariable model 2 attenuated the association between sleep duration $\leq 5 \mathrm{~h}$ and hypercholesterolaemia, but it still remained significant; however, the association between sleep duration $\geq 9 \mathrm{~h}$ and hypercholesterolaemia lost significance after adjusting for potential confounders in multivariable model 1 . Conversely, among men, there was a non-significant inverse association between sleep duration $\geq 8 \mathrm{~h}$ and hypercholesterolaemia in the age-adjusted model. This inverse association became significant and accentuated after adjusting for covariates in multivariable model 1 , and additional adjustment for mediators in multivariable model 2 ( $P$ interaction by gender $=0.003)$.

Table 4 shows the association between sleep duration and hypercholesterolaemia for men and women by age. In women, there was a significant positive association between sleep durations $\leq 5$ and $\geq 9 \mathrm{~h}$ and hypercholesterolaemia among those aged $<60$ years. In men, there was a significant positive association between sleep durations of 6 and $8 \mathrm{~h}$ and hypercholesterolaemia among those aged $<60$ years. However, there were no significant interactions by age among men, women or the entire sample ( $P$ interaction by age $=0.1$ in men, 0.2 in women and 0.8 in the entire sample).

Table 5 shows the association between sleep duration and hypercholesterolaemia for men and women by race/ethnic group. The positive association between sleep duration $\leq 5 \mathrm{~h}$ and hypercholesterolaemia in women, and the inverse association between sleep duration $\geq 8 \mathrm{~h}$ and hypercholesterolaemia in men appeared to be stronger in race/ethnic groups other than non-Hispanic Whites. However, no significant interactions were observed in the association between sleep duration and hypercholesterolaemia by race/ethnicity in men, women or the entire sample ( $P$ interaction by race $=0.1$ in men, 0.2 in women and 0.06 in the entire sample).

In a supplementary analysis, the authors explored the association between sleep duration and overweight/obesity, a potential mediating factor of hypercholesterolaemia. Women who reported sleep duration $\leq 5 \mathrm{~h}$ had a higher prevalence of overweight/obesity (68.9\%) compared with women who reported sleep duration of $7 \mathrm{~h}(56.9 \%)$. On the other hand, in men, the prevalence of overweight/obesity was lower among those who reported sleep duration $\geq 8 \mathrm{~h}(67.0 \%)$ compared with those who reported sleep duration of $7 \mathrm{~h}(72.8 \%)$. Compared with those who reported sleep duration of $7 \mathrm{~h} /$ night, the multivariable OR of overweight/obesity was 1.32 (95\% CI 1.06-1.65) among women with sleep duration $\leq 5 \mathrm{~h}$, and 0.72 (95\% CI 0.61-0.86) and 0.66 (95\% CI 0.50-0.86) among men with sleep durations of 8 and $\geq 9 \mathrm{~h}$. No significant association was found between sleep durations of 6,8 and $\geq 9$ $\mathrm{h}$ and overweight/obesity in women, and sleep durations of $\leq 5$ and $6 \mathrm{~h}$ and overweight/ obesity in men.

\section{Discussion}

In a nationally representative sample of US adults, sleep duration $\leq 5 \mathrm{~h}$ was found to be positively associated with hypercholesterolaemia in women. In contrast, sleep duration $\geq 8 \mathrm{~h}$ 
was inversely associated with hypercholesterolaemia in men. These associations in men and women were independent of age, race/ethnicity, smoking, alcohol intake, physical activity, psychological distress, BMI, diabetes mellitus and hypertension. In subgroup analyses, the positive association between sleep duration $\leq 5 \mathrm{~h}$ and hypercholesterolaemia in women, and the inverse association between sleep duration $\geq 8 \mathrm{~h}$ and hypercholesterolaemia in men were found to be stronger in adults aged $<60$ years and race/ethnic groups other than nonHispanic Whites.

The mean sleep duration reported in the current study ( $7.1 \mathrm{~h}$ in men and $7.2 \mathrm{~h}$ in women) is similar to that reported in the National Health and Nutrition Examination Survey 2005/06 (6.8 $\mathrm{h}$ in men and $7.0 \mathrm{~h}$ in women) [23]. The prevalence of self-reported hypercholesterolaemia in the current study (30.4 in men and $30.6 \%$ in women) is similar to that reported by the SHIELD screening survey (26.9 in men and $24.8 \%$ in women) conducted in 2004 in the USA [24]. However, this is significantly lower than that reported in NHANES $1999 / 2002$ (60.2 in men and $45.8 \%$ in women) [24].

Previous studies of the association between sleep duration and hypercholesterolaemia have reported mixed results $[12,15,16]$. In a cross-sectional study of 8860 adults aged $40-45$ years in the USA, Bjorvatn et al. found that self-reported sleep duration was not associated with hypercholesterolaemia after adjusting for gender, BMI and smoking [12]. In a crosssectional study of 1580 middle-aged Japanese male office workers, Nakanishi et al. found no association between self-reported sleep duration and hypercholesterolaemia [15]. In a sample of 768 elderly adults aged 57-95 years in the Netherlands, van den Berg et al. found that actigraphy-assessed longer sleep duration was positively associated with hypercholesterolaemia [16]. Experimental studies found that sleep restriction [11] and total sleep time [10] were associated with hypercholesterolaemia in healthy volunteers.

The current study found gender differences in the association between sleep duration and hypercholesterolaemia, with a positive association found between sleep duration $\leq 5 \mathrm{~h}$ and hypercholesterolaemia in women, and an inverse association found between sleep duration $\geq 8 \mathrm{~h}$ and hypercholesterolaemia in men. Few other studies have reported gender differences in the association between sleep duration and hypercholesterolaemia. In a prospective study of 14,257 adolescents aged 7-12 years at baseline, Gangwisch et al. reported that short sleep duration was associated with self-reported hypercholesterolaemia after a follow-up period of 7 years [13]. However, the association was only significant in females. In a cross-sectional study of 1666 men and 2329 women aged $\geq 20$ years in Japan, Kaneita et al. found that both short and long sleep durations were positively associated with dyslipidaemia in women; in contrast, sleep duration $\geq 8 \mathrm{~h}$ was found to be inversely associated with dyslipidaemia in men [14]. The present findings in women extend the positive association between short sleep duration and hypercholesterolaemia reported by Gangwisch et al. among adolescents to adults in the USA [13]. The present findings in men and women are consistent, at least in part, with those reported by Kaneita et al. [14]; however, the present study did not observe an association between long sleep duration and hypercholesterolaemia in women aged $\geq 60$ years.

The effect of short sleep duration on lipid metabolism is likely to be mediated by a combination of hormonal and metabolic alterations, including upregulation of appetite and reduced insulin sensitivity [25] and inflammation [26]. Based on the data from the population-based Wisconsin Sleep Cohort Study, Taheri et al. reported that total sleep time was inversely associated with ghrelin and positively associated with leptin, an appetiteinhibiting hormone [7]. In a small experimental study involving 10 healthy postmenopausal women, sleep restriction for 3 days increased inflammatory cells and cholesterol levels [11]. Several studies have shown that short sleep duration is associated with risk factors of 
hypercholesterolaemia including weight gain [27], obesity [28] and diabetes [5]. Studies have shown that long sleep duration is inversely associated with obesity in children [29], adolescents [30] and adults [31]. In the current study, the higher prevalence of overweight/ obesity among women with sleep duration $\leq 5 \mathrm{~h}$ and the lower prevalence of overweight/ obesity among men with sleep duration $\geq 8 \mathrm{~h}$ suggest that at least part of the association between sleep duration and hypercholesterolaemia is mediated by overweight/obesity in both men and women.

The reason for the observed gender difference in the association between sleep duration and hypercholesterolaemia is not clear. It could be due to sex-related differences in the sleep pattern [32], differential self-reporting of sleep [33] or hormonal influences [34]. Studies have reported that women are more likely to be affected by short sleep duration than men [34]. Knutson et al. reported that longer sleep duration was associated with a lower risk of obesity in adolescent males but not females [35]. It is possible that men with long sleep duration may have less job stress [36] or spend less time watching television or surfing the Internet [31]. In the CARDIA study, watching television was shown to be associated with several cardiovascular risk factors including smoking, obesity and physical inactivity [31].

The major strengths of the current study include its large sample size and the availability of information on potential confounders and mediators. However, this study has some limitations. First, the cross-sectional nature of the study limits the drawing of causal inferences. Second, assessment of self-reported sleep duration could have resulted in nondifferential misclassification of exposure, which may have attenuated the effect estimates. Further, a single question to assess hypercholesterolaemia may have under- or overestimated cholesterol status. In the third National Health and Nutrition Examination Survey (NHANES III), self-reported hypercholesterolaemia indicated a prevalence of $32 \%$ whereas the true prevalence was $59 \%$, thus underestimating approximately $46 \%$ of the true prevalence [37]. It is also possible that individuals who have been told that they have hypercholesterolaemia by a health professional may have made subsequent lifestyle changes to reverse the problem, thus overestimating the true prevalence. However, in NHANES III, the inclusion of individuals who had made lifestyle changes in the diagnosis only had a minimal effect on prevalence [37]. Third, although this study accounted for several confounders, the possibility of residual confounding due to unmeasured variables (e.g. job stress, sleep quality, daytime sleepiness, diagnosed sleep disorders and obstructive sleep apnoea) or incompletely adjusted covariates (e.g. self-reported physical activity, smoking, psychological distress) cannot be excluded.

In conclusion, this study investigated the association between sleep duration and hypercholesterolaemia in a nationally representative sample of US men and women. If confirmed by future prospective studies, these findings may have implications for the evaluation of sleep habits in cholesterol screening programmes, and tailoring gender-specific interventions to lower the cholesterol level.

\section{References}

1. Shankar A, Koh WP, Yuan JM, Lee HP, Yu MC. Sleep duration and coronary heart disease mortality among Chinese adults in Singapore: a population-based cohort study. Am J Epidemiol. 2008; 168:1367-1373. [PubMed: 18952563]

2. Sabanayagam C, Shankar A. Sleep duration and cardiovascular disease: results from the National Health Interview Survey. Sleep. 2010; 33:1037-1042. [PubMed: 20815184]

3. Ayas NT, White DP, Manson JE, Stampfer MJ, Speizer FE, Malhotra A, et al. A prospective study of sleep duration and coronary heart disease in women. Arch Intern Med. 2003; 163:205-209. [PubMed: 12546611] 
4. Gottlieb DJ, Punjabi NM, Newman AB, Resnick HE, Redline S, Baldwin CM, et al. Association of sleep time with diabetes mellitus and impaired glucose tolerance. Arch Intern Med. 2005; 165:863867. [PubMed: 15851636]

5. Chaput JP, Despres JP, Bouchard C, Astrup A, Tremblay A. Sleep duration as a risk factor for the development of type 2 diabetes or impaired glucose tolerance: analyses of the Quebec Family Study. Sleep Med. 2009; 10:919-924. [PubMed: 19332380]

6. Gottlieb DJ, Redline S, Nieto FJ, Baldwin CM, Newman AB, Resnick HE, et al. Association of usual sleep duration with hypertension: the Sleep Heart Health Study. Sleep. 2006; 29:1009-1014. [PubMed: 16944668]

7. Taheri S, Lin L, Austin D, Young T, Mignot E. Short sleep duration is associated with reduced leptin, elevated ghrelin, and increased body mass index. PLoS Med. 2004; 1:e62. [PubMed: 15602591]

8. Adamkova V, Hubacek JA, Lanska V, Vrablik M, Kralova LI, Suchanek P, et al. Association between duration of the sleep and body weight. Physiol Res. 2009; 58(Suppl. 1):S27-S31. [PubMed: 19857033]

9. Third Report of the National Cholesterol Education Program (NCEP). Expert Panel on Detection, Evaluation, and Treatment of High Blood Cholesterol in Adults (Adult Treatment Panel III) final report. Circulation. 2002; 106:3143-3421. [PubMed: 12485966]

10. Ekstedt M, Akerstedt T, Soderstrom M. Microarousals during sleep are associated with increased levels of lipids, cortisol, and blood pressure. Psychosom Med. 2004; 66:925-931. [PubMed: 15564359]

11. Kerkhofs M, Boudjeltia KZ, Stenuit P, Brohee D, Cauchie P, Vanhaeverbeek M. Sleep restriction increases blood neutrophils, total cholesterol and low density lipoprotein cholesterol in postmenopausal women: a preliminary study. Maturitas. 2007; 56:212-215. [PubMed: 16950577]

12. Bjorvatn B, Sagen IM, Oyane N, Waage S, Fetveit A, Pallesen S, et al. The association between sleep duration, body mass index and metabolic measures in the Hordaland Health Study. J Sleep Res. 2007; 16:66-76. [PubMed: 17309765]

13. Gangwisch JE, Malaspina D, Babiss LA, Opler MG, Posner K, Shen S, et al. Short sleep duration as a risk factor for hypercholesterolemia: analyses of the National Longitudinal Study of Adolescent Health. Sleep. 2010; 33:956-961. [PubMed: 20614855]

14. Kaneita Y, Uchiyama M, Yoshiike N, Ohida T. Associations of usual sleep duration with serum lipid and lipoprotein levels. Sleep. 2008; 31:645-652. [PubMed: 18517035]

15. Nakanishi N, Nakamura K, Ichikawa S, Suzuki K, Tatara K. Relationship between lifestyle and serum lipid and lipoprotein levels in middle-aged Japanese men. Eur J Epidemiol. 1999; 15:341348. [PubMed: 10414374]

16. van den Berg JF, Miedema HM, Tulen JH, Neven AK, Hofman A, Witteman JC, et al. Long sleep duration is associated with serum cholesterol in the elderly: the Rotterdam Study. Psychosom Med. 2008; 70:1005-1011. [PubMed: 18842743]

17. Williams CJ, Hu FB, Patel SR, Mantzoros CS. Sleep duration and snoring in relation to biomarkers of cardiovascular disease risk among women with type 2 diabetes. Diabetes Care. 2007; 30:12331240. [PubMed: 17322482]

18. National Center for Health Statistics. [(last accessed 10/07/2010)] Data file documentation, National Health Interview Survey, 2008, 2009. Available at: http://ftp.cdc.gov/pub/Health_Statistics/NCHS/Dataset_Documentation/NHIS/2008/srvydesc.pdf

19. Centers for Disease Control and Prevention. [(last accessed 18/04/2011)] Physical activity for everyone. 2011. Available at http://www.cdc.gov/physicalactivity/everyone/guidelines/adults.html

20. Kessler RC, Andrews G, Colpe LJ, Hiripi E, Mroczek DK, Normand SL, et al. Short screening scales to monitor population prevalences and trends in non-specific psychological distress. Psychol Med. 2002; 32:959-976. [PubMed: 12214795]

21. Tamakoshi A, Ohno Y. Self-reported sleep duration as a predictor of all-cause mortality: results from the JACC study, Japan. Sleep. 2004; 27:51-54. [PubMed: 14998237]

22. Kripke DF, Garfinkel L, Wingard DL, Klauber MR, Marler MR. Mortality associated with sleep duration and insomnia. Arch Gen Psychiatry. 2002; 59:131-136. [PubMed: 11825133] 
23. Ram S, Seirawan H, Kumar SK, Clark GT. Prevalence and impact of sleep disorders and sleep habits in the United States. Sleep Breath. 2010; 14:63-70. [PubMed: 19629554]

24. Bays HE, Bazata DD, Clark NG, Gavin JR III, Green AJ, Lewis SJ, et al. Prevalence of selfreported diagnosis of diabetes mellitus and associated risk factors in a national survey in the US population: SHIELD (Study to Help Improve Early evaluation and management of risk factors Leading to Diabetes). BMC Public Health. 2007; 7:277. [PubMed: 17915014]

25. Leproult R, Van CE. Role of sleep and sleep loss in hormonal release and metabolism. Endocr Dev. 2010; 17:11-21. [PubMed: 19955752]

26. Hayes AL, Xu F, Babineau D, Patel SR. Sleep duration and circulating adipokine levels. Sleep. 2011; 34:147-152. [PubMed: 21286230]

27. Patel SR, Hu FB. Short sleep duration and weight gain: a systematic review. Obesity (Silver Spring). 2008; 16:643-653. [PubMed: 18239586]

28. Hasler G, Buysse DJ, Klaghofer R, Gamma A, Ajdacic V, Eich D, et al. The association between short sleep duration and obesity in young adults: a 13-year prospective study. Sleep. 2004; 27:661-666. [PubMed: 15283000]

29. Van CE, Knutson KL. Sleep and the epidemic of obesity in children and adults. Eur J Endocrinol. 2008; 159(Suppl. 1):S59-S66. [PubMed: 18719052]

30. Eisenmann JC, Ekkekakis P, Holmes M. Sleep duration and overweight among Australian children and adolescents. Acta Paediatr. 2006; 95:956-963. [PubMed: 16882569]

31. Vioque J, Torres A, Quiles J. Time spent watching television, sleep duration and obesity in adults living in Valencia, Spain. Int J Obes Relat Metab Disord. 2000; 24:1683-1688. [PubMed: 11126224]

32. Fukuda N, Honma H, Kohsaka M, Kobayashi R, Sakakibara S, Kohsaka S, et al. Gender difference of slow wave sleep in middle aged and elderly subjects. Psychiatry Clin Neurosci. 1999; 53:151153. [PubMed: 10459675]

33. Baldwin CM, Kapur VK, Holberg CJ, Rosen C, Nieto FJ. Associations between gender and measures of daytime somnolence in the Sleep Heart Health Study. Sleep. 2004; 27:305-311. [PubMed: 15124727]

34. Dzaja A, Arber S, Hislop J, Kerkhofs M, Kopp C, Pollmacher T, et al. Women's sleep in health and disease. J Psychiatr Res. 2005; 39:55-76. [PubMed: 15504424]

35. Knutson KL. Sex differences in the association between sleep and body mass index in adolescents. J Pediatr. 2005; 147:830-834. [PubMed: 16356441]

36. Siegrist J, Peter R, Cremer P, Seidel D. Chronic work stress is associated with atherogenic lipids and elevated fibrinogen in middle-aged men. J Intern Med. 1997; 242:149-156. [PubMed: 9279292]

37. Natarajan S, Lipsitz SR, Nietert PJ. Self-report of high cholesterol: determinants of validity in U.S. adults. Am J Prev Med. 2002; 23:13-21. [PubMed: 12093418] 
Table 1

Baseline characteristics of the study population by hypercholesterolaemic status.

\begin{tabular}{|c|c|c|c|}
\hline Characteristic & $\begin{array}{c}\text { With } \\
\text { hypercholesterolemia } \\
\text { absent } \\
(n=11,074)\end{array}$ & $\begin{array}{c}\text { Without } \\
\text { hypercholesterolemia } \\
(n=5578)\end{array}$ & $P$-value \\
\hline Age $\geq 60$ years $(\%)$ & 21.5 & 42.0 & $<0.0001$ \\
\hline Female $(\%)$ & 52.8 & 51.9 & 0.4 \\
\hline Race/ethnicity (\%) & & & $<0.0001$ \\
\hline Non-Hispanic White & 67.6 & 75.7 & \\
\hline Non-Hispanic Black & 12.5 & 9.1 & \\
\hline Mexican American & 13.0 & 10.1 & \\
\hline Other & 6.9 & 5.1 & \\
\hline Education (\%) & & & $<0.0001$ \\
\hline Less than high school & 15.6 & 18.6 & \\
\hline High school & 32.3 & 33.8 & \\
\hline More than high school & 52.1 & 47.6 & \\
\hline Smoking $(\%)$ & & & $<0.0001$ \\
\hline Never smoker & 60.0 & 51.4 & \\
\hline Former smoker & 21.0 & 31.2 & \\
\hline Current smoker & 19.0 & 17.4 & \\
\hline Drinking $(\%)$ & & & $<0.0001$ \\
\hline Never drinker & 20.9 & 18.2 & \\
\hline Former drinker & 13.5 & 20.0 & \\
\hline Current drinker & 65.6 & 61.8 & \\
\hline Body mass index $(\%)$ & & & $<0.0001$ \\
\hline Underweight $\left(<18.5 \mathrm{~kg} / \mathrm{m}^{2}\right)$ & 2.2 & 0.6 & \\
\hline Normal $\left(18.5-24.9 \mathrm{~kg} / \mathrm{m}^{2}\right)$ & 37.0 & 24.8 & \\
\hline Overweight (25-29.9 kg/m²) & 32.9 & 37.7 & \\
\hline Obese $\left(\geq 30 \mathrm{~kg} / \mathrm{m}^{2}\right)$ & 28.0 & 36.9 & \\
\hline No regular exercise $(\%)$ & 73.4 & 77.8 & $<0.0001$ \\
\hline Psychological distress (\%) & 9.8 & 12.5 & $<0.0001$ \\
\hline Diabetes mellitus (\%) & 6.7 & 16.6 & $<0.0001$ \\
\hline Hypertension (\%) & 25.3 & 54.0 & $<0.0001$ \\
\hline
\end{tabular}




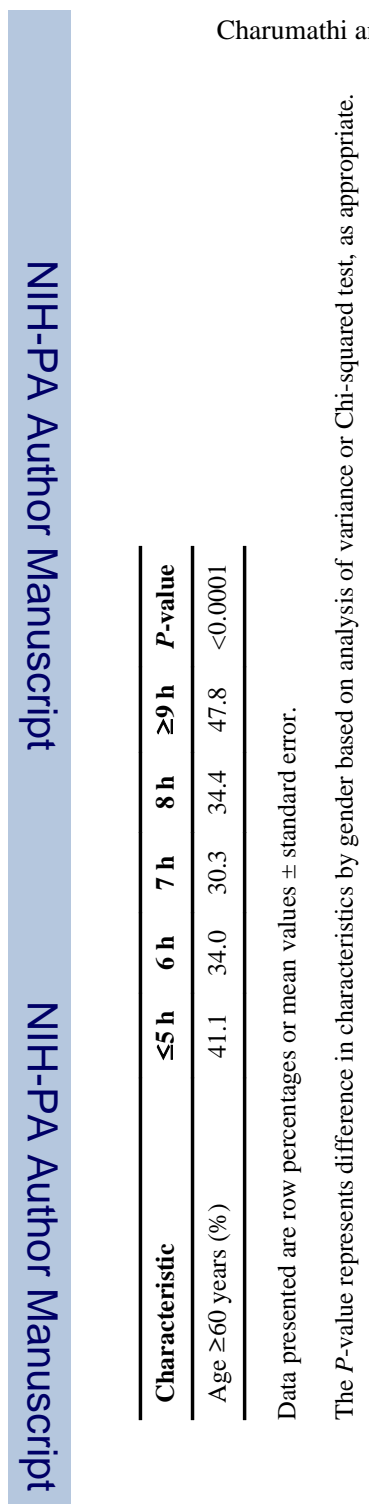

Sleep Med. Author manuscript; available in PMC 2013 February 1. 
Table 3

Association between sleep duration and hypercholesterolaemia by gender.

\begin{tabular}{|c|c|c|c|c|}
\hline Sleep duration (h) & $\begin{array}{l}\text { No. at risk } \\
\quad \text { (cases) }\end{array}$ & $\begin{array}{l}\text { Age-adjusted } \\
\text { OR }(95 \% \text { CI })\end{array}$ & $\begin{array}{c}\text { Multivariable-adjusted } \\
\text { OR (95\% CI) } \\
\text { Model } 1^{b}\end{array}$ & $\begin{array}{c}\text { Multivariable-adjusted } \\
\text { OR (95\% CI) } \\
\text { Model } 2^{c}\end{array}$ \\
\hline \multicolumn{5}{|l|}{$\operatorname{Men}(n=7103)$} \\
\hline$\leq 5$ & $547(180)$ & $0.92(0.73-1.15)$ & $0.88(0.69-1.12)$ & $0.84(0.66-1.06)$ \\
\hline 6 & $1528(501)$ & $0.92(0.78-1.08)$ & $0.86(0.75-1.05)$ & $0.85(0.72-1.01)$ \\
\hline 7 & $2274(746)$ & 1 (referent) & 1 (referent) & 1 (referent) \\
\hline 8 & $2166(719)$ & $0.80(0.69-0.93)$ & $0.82(0.71-0.96)$ & $0.80(0.69-0.94)$ \\
\hline$\geq 9$ & $588(225)$ & $0.86(0.68-1.09)$ & $0.80(0.61-1.00)$ & $0.78(0.60-1.00)$ \\
\hline \multicolumn{5}{|l|}{ Women $(n=9549)$} \\
\hline$\leq 5$ & $856(352)$ & $1.47(1.22-1.78)$ & $1.39(1.15-1.68)$ & $1.27(1.04-1.54)$ \\
\hline 6 & $1943(652)$ & $1.16(1.01-1.34)$ & $1.13(0.98-1.32)$ & $1.11(0.95-1.30)$ \\
\hline 7 & $2827(863)$ & 1 (referent) & 1 (referent) & 1 (referent) \\
\hline 8 & 3018 (969) & $0.99(0.87-1.13)$ & $0.98(0.86-1.12)$ & $0.99(0.87-1.14)$ \\
\hline$\geq 9$ & $905(371)$ & $1.30(1.08-1.57)$ & $1.20(0.98-1.45)$ & $1.14(0.94-1.39)$ \\
\hline
\end{tabular}

OR, odds ratio; $\mathrm{CI}$, confidence interval.

${ }^{a}$ No. at risk represents the total number of subjects in each category (i.e. the denominator), and cases indicates the number of cases in each category (i.e. the numerator).

${ }^{b}$ Adjusted for age (years), race/ethnicity (non-Hispanic White, non-Hispanic Black, Hispanic-American, other), education (less than high school, high school, more than high school), smoking (never, former, current), alcohol intake (never, former, current), physical inactivity (absent, present) and psychological distress (absent, present).

${ }^{c}$ Adjusted for variables in model 1 plus diabetes mellitus (absent, present), hypertension (absent, present) and overweight (absent, present).

$P$ interaction (sleep duration $*$ female) $=0.003$ 
Table 4

Association between sleep duration and hypercholesterolaemia by gender and age group.

\begin{tabular}{|c|c|c|c|c|}
\hline \multirow[b]{2}{*}{ Sleep duration (h) } & \multicolumn{2}{|c|}{ Men $(n=7103)$} & \multicolumn{2}{|c|}{ Women $(n=9549)$} \\
\hline & 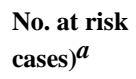 & $\begin{array}{l}\text { Multivariate model } 2 \\
\text { OR }(95 \% \mathrm{CI})^{b}\end{array}$ & $\mathbf{N}$ (cases) & $\begin{array}{l}\text { Multivariate model } 2 \\
\text { OR }(95 \% \text { CI })^{b}\end{array}$ \\
\hline \multicolumn{5}{|l|}{$\begin{array}{l}\text { Age }<60 \text { years } \\
(n=11,270)\end{array}$} \\
\hline$\leq 5$ & 434 (127) & $0.79(0.60-1.04)$ & 559 (199) & $1.51(1.17-1.95)$ \\
\hline 6 & 1188 (333) & $0.76(0.62-0.94)$ & $1352(343)$ & $1.13(0.92-1.38)$ \\
\hline 7 & $1703(490)$ & 1 (referent) & 2025 (477) & 1 (referent) \\
\hline 8 & $1366(347)$ & $0.79(0.65-0.97)$ & $1929(453)$ & $1.04(0.86-1.25)$ \\
\hline$\geq 9$ & $278(78)$ & $0.76(0.53-1.10)$ & $436(146)$ & $1.51(1.16-1.98)$ \\
\hline \multicolumn{5}{|l|}{$\begin{array}{l}\text { Age } \geq 60 \text { years } \\
(n=5382)\end{array}$} \\
\hline$\leq 5$ & $113(53)$ & $0.84(0.52-1.34)$ & 297 (153) & $0.94(0.67-1.32)$ \\
\hline 6 & $340(168)$ & $1.13(0.82-1.55)$ & $591(309)$ & $1.11(0.86-1.45)$ \\
\hline 7 & $571(256)$ & 1 (referent) & $802(386)$ & 1 (referent) \\
\hline 8 & $88(372)$ & $0.97(0.77-1.21)$ & $1089(516)$ & $0.95(0.76-1.18)$ \\
\hline$\geq 9$ & $310(147)$ & $1.04(0.74-1.46)$ & $469(225)$ & $0.91(0.68-1.23)$ \\
\hline
\end{tabular}

OR, odds ratio; $\mathrm{CI}$, confidence interval.

${ }^{a}$ No. at risk represents the total number of subjects in each category (i.e. the denominator), and cases indicates the number of cases in each category (i.e. the numerator).

${ }^{b}$ Adjusted for race/ethnicity (non-Hispanic White, non-Hispanic Black, Hispanic-American, other), education (less than high school, high school, more than high school), smoking (never, former, current), alcohol intake (never, former, current), physical inactivity (absent, present), psychological distress (absent, present), diabetes mellitus (absent, present), hypertension (absent, present) and overweight (absent, present).

$P$ interaction (sleep duration*age) was 0.8 in the whole population, 0.1 in men and 0.2 in women. 
Table 5

Association between sleep duration and hypercholesterolaemia by gender and race/ethnicity.

\begin{tabular}{|c|c|c|c|c|}
\hline \multirow[b]{2}{*}{ Sleep duration (h) } & \multicolumn{2}{|c|}{$\operatorname{Men}(n=7103)$} & \multicolumn{2}{|c|}{ Women $(n=9549)$} \\
\hline & $\begin{array}{l}\text { No. at risk } \\
\text { (cases) }{ }^{a}\end{array}$ & $\begin{array}{l}\text { Multivariate model } 2 \\
\text { OR }(95 \% \mathrm{CI})^{b}\end{array}$ & $\mathbf{N}$ (cases) & $\begin{array}{l}\text { Multivariate model } 2 \\
\text { OR }(95 \% \mathrm{CI})^{b}\end{array}$ \\
\hline \multicolumn{5}{|l|}{$\begin{array}{l}\text { Non-Hispanic White } \\
(n=10,395)\end{array}$} \\
\hline$\leq 5$ & $327(120)$ & $0.86(0.65-1.13)$ & 474 (199) & $1.13(0.88-1.44)$ \\
\hline 6 & $954(330)$ & $0.84(0.69-1.02)$ & $1023(364)$ & $1.19(0.98-1.45)$ \\
\hline 7 & $1537(543)$ & 1 (referent) & $1112(417)$ & 1 (referent) \\
\hline 8 & $1377(518)$ & $0.86(0.72-1.03)$ & $1832(656)$ & $1.02(0.87-1.19)$ \\
\hline$\geq 9$ & $383(161)$ & $0.85(0.63-1.14)$ & $574(266)$ & $1.24(0.99-1.56)$ \\
\hline \multicolumn{5}{|l|}{$\begin{array}{l}\text { Other race/ethnicity } \\
(n=6257)\end{array}$} \\
\hline$\leq 5$ & $220(60)$ & $0.71(0.47-1.08)$ & $382(153)$ & $1.53(1.11-2.12)$ \\
\hline 6 & $574(171)$ & $0.81(0.60-1.09)$ & $831(235)$ & $0.89(0.67-1.19)$ \\
\hline 7 & $737(203)$ & 1 (referent) & $1002(263)$ & 1 (referent) \\
\hline 8 & $789(201)$ & $0.65(0.48-0.86)$ & $1186(313)$ & $0.93(0.74-1.17)$ \\
\hline$\geq 9$ & $205(64)$ & $0.63(0.40-0.99)$ & $331(105)$ & $0.88(0.60-1.29)$ \\
\hline
\end{tabular}

OR, odds ratio; $\mathrm{CI}$, confidence interval.

${ }^{a}$ No. at risk represents the total number of subjects in each category (i.e. the denominator), and cases indicates the number of cases in each category (i.e. the numerator).

${ }^{b}$ Adjusted for age (years), education (less than high school, high school, more than high school), smoking (never, former, current), alcohol intake (never, former, current), physical inactivity (absent, present), psychological distress (absent, present), diabetes mellitus (absent, present), hypertension (absent, present) and overweight (absent, present)

$P$ interaction (sleep duration* race/ethnicity) was 0.06 in the whole population, 0.2 in men and 0.1 in women. 